\title{
Diverse effects of renal denervation on ventricular hypertrophy and blood pressure in DOCA-salt hypertensive rats
}

A.M. Cabral, I.F. Silva,

C.R. Gardioli, H. Mauad and E.C. Vasquez
Departamento de Ciências Fisiológicas, Centro Biomédico, Universidade Federal do Espírito Santo, Vitória, ES, Brasil

\section{Correspondence}

A.M. Cabral

Departamento de Ciências

Fisiológicas

Centro Biomédico, UFES

Av. Marechal Campos, 1468

29040-090 Vitória, ES

Brasil

Fax: 55 (027) 335-7330

Research supported by CNPq and FINEP.

Received September 23, 1997

Accepted January 26, 1998

\section{Abstract}

Cardiac hypertrophy that accompanies hypertension seems to be a phenomenon of multifactorial origin whose development does not seem to depend on an increased pressure load alone, but also on local growth factors and cardioadrenergic activity. The aim of the present study was to determine if sympathetic renal denervation and its effects on arterial pressure level can prevent cardiac hypertrophy and if it can also delay the onset and attenuate the severity of deoxycorticosterone acetate (DOCA)-salt hypertension. DOCA-salt treatment was initiated in rats seven days after uninephrectomy and contralateral renal denervation or sham renal denervation. DOCA $(15 \mathrm{mg} / \mathrm{kg}, s c)$ or vehicle (soybean oil, $0.25 \mathrm{ml}$ per animal) was administered twice a week for two weeks. Rats treated with DOCA or vehicle (control) were provided drinking water containing $1 \% \mathrm{NaCl}$ and $0.03 \% \mathrm{KCl}$. At the end of the treatment period, mean arterial pressure (MAP) and heart rate measurements were made in conscious animals. Under ether anesthesia, the heart was removed and the right and left ventricles (including the septum) were separated and weighed. DOCA-salt treatment produced a significant increase in left ventricular weight/body weight ( $\mathrm{LVW} / \mathrm{BW}$ ) ratio $(2.44 \pm 0.09 \mathrm{mg} / \mathrm{g})$ and right ventricular weight/body weight $(\mathrm{RVW} / \mathrm{BW})$ ratio $(0.53 \pm 0.01 \mathrm{mg} / \mathrm{g})$ compared to control (1.92 \pm 0.04 and $0.48 \pm 0.01 \mathrm{mg} / \mathrm{g}$, respectively) rats. MAP was significantly higher $(39 \%)$ in DOCA-salt rats. Renal denervation prevented $(\mathrm{P}>0.05)$ the development of hypertension in DOCA-salt rats but did not prevent the increase in LVW/BW $(2.27 \pm 0.03 \mathrm{mg} / \mathrm{g})$ and RVW/BW $(0.52 \pm 0.01 \mathrm{mg} / \mathrm{g})$. We have shown that the increase in arterial pressure level is not responsible for cardiac hypertrophy, which may be more related to other events associated with DOCA-salt hypertension, such as an increase in cardiac sympathetic activity.
Left ventricular hypertrophy (LVH) that accompanies arterial hypertension is considered to be an occurrence of multifactorial origin involving neurohormonal mechanisms. The development of LVH does not seem to depend only on an increased pressure load to the heart, but also on local growth factors

\section{Key words}

- Ventricular hypertrophy

- Renal denervation

- DOCA-salt hypertension

- Blood pressure and cardioadrenergic activity (1). Although local renin-angiotensin systems may influence cardiac myocyte growth and therefore contribute to the development of $\operatorname{LVH}(2,3)$, a body of evidence has accumulated showing that sympathetic activity may be effective in inducing the cardiac hypertrophy as- 
sociated with various forms of arterial hypertension. The role played by the sympathetic nervous system in the development of cardiac hypertrophy is well understood $(4,5)$, but not the role played by high blood pressure. For example, hyperactivity of the sympathetic nervous system induced by sinoaortic denervation $(6,7)$ even in the acute phase is capable of eliciting $\mathrm{LVH}$ in male rats (8). Furthermore, chronic administration of the sympathomimetic drug isoproterenol produces cardiac hypertrophy in rats (9-12). However, little is known about the influence of renal sympathetic nerve activity on LVH. It is known that chronic sympathetic renal nerve denervation delays the onset and attenuates the severity of deoxycorticosterone acetate (DOCA)-salt hypertension (13). Thus, the objective of the present study was to determine whether sympathetic renal denervation and its effects on the pressure load can prevent cardiac hypertrophy and whether it can also delay the onset and attenuate the severity of DOCA-salt hypertension.

Male adult Wistar rats (240-260 g) were subjected to unilateral nephrectomy (right kidney) under anesthesia with ketamine (30 $\mathrm{mg} / \mathrm{kg}, \mathrm{im}$ ) in combination with xylazine (3 $\mathrm{mg} / \mathrm{kg}, \mathrm{im})$. During the same surgical procedure the left kidney was subjected to sympathetic denervation or a sham operation. Renal denervation was performed via a lateral flank incision. The renal artery and vein were stripped of the adventitia, the renal nerve bundles were cut and the vessels were coated with a solution of $10 \%$ phenol in absolute ethanol as previously described (14). DOCA-salt treatment was initiated seven days later. DOCA (Sigma Chemical Co., St. Louis, MO, $15 \mathrm{mg} / \mathrm{kg}, s c$ ) or vehicle (soybean oil, $0.25 \mathrm{ml}$ per animal) was administered twice a week for 15 days. Rats were housed in semi-metabolic cages, treated with DOCA or vehicle (control) and provided with drinking water containing $1 \% \mathrm{NaCl}$ and $0.03 \% \mathrm{KCl}$. The control group included nine uninephrectomized and sham-denervated rats. DOCA-salt groups included 11 rats uninephrectomized and sham-denervated (DOCA-salt) only, and 9 rats submitted to uninephrectomy plus contralateral renal denervation (DOCA-salt-denervated) rats.

At the end of the treatment period, rats were anesthetized with ether and instrumented with catheters (PE-50) in the left femoral artery and vein. The polyethylene catheter was tunneled to exit at the back of the neck, flushed and filled with $40 \mathrm{U} / \mathrm{ml}$ heparinized saline. Six hours later, mean arterial pressure (MAP) and heart rate (HR) measurements were made in conscious animals using a pressure transducer (P23XL, Statham, Valley View, OH) coupled to a polygraph (RS 3400, Gould Instruments Systems, Valley View, OH). The animals in their home cages were allowed to acclimatize to the laboratory for $1 \mathrm{~h}$ while they were being connected for measurements. After the hemodynamic variables were recorded, the animals were anesthetized with ether, the heart was removed and the right and left ventricles (including the septum) were separated and weighed. Statistical analysis of data was performed by two-way analysis of variance followed by a post-hoc protected Tukey's test. All experiments were conducted in conformity with international guidelines for biomedical research involving animals.

Fifteen days of DOCA-salt treatment resulted in a significant increase in left ventricular weight/body weight (LVW/BW) ratio $(2.44 \pm 0.09 \mathrm{mg} / \mathrm{g})$ and right ventricular weight/body weight ( $\mathrm{RVW} / \mathrm{BW})$ ratio $(0.53$ $\pm 0.01 \mathrm{mg} / \mathrm{g}$ ) compared to age-matched control $(1.92 \pm 0.04$ and $0.48 \pm 0.01 \mathrm{mg} / \mathrm{g}$, respectively) rats as illustrated in Figure 1. As shown in Table 1, MAP was significantly higher (39\%) in DOCA-salt rats. Renal denervation significantly prevented the development and high level of hypertension in the DOCA-salt rats. In contrast, DOCA-salt administration still caused a significant increase in LVW/BW ratio $(2.27 \pm 0.03 \mathrm{mg} / \mathrm{g})$ and $\mathrm{RVW} / \mathrm{BW}$ ratio $(0.52 \pm 0.01 \mathrm{mg} / \mathrm{g})$ in renal- 
denervated rats compared to age-matched controls (Figure 1), even though the MAP did not reach the hypertension level observed in the DOCA-salt group. There was no significant difference in daily saline intake between the DOCA-salt $(50 \pm 5 \mathrm{ml})$ and DOCAsalt-denervated $(47 \pm 6 \mathrm{ml})$ rats, whose values were significantly higher than observed in the control $(29 \pm 5 \mathrm{ml})$ group.

The present data show that sympathetic renal denervation does not prevent the development of DOCA-salt-induced left and right ventricular hypertrophy despite preventing the high level of hypertension caused by DOCA-salt rats. The long-term control of arterial pressure is thought to be regulated by the renal control of fluid and electrolyte balance (15), and evidence has accumulated suggesting that renal sodium excretion is impaired, at least in part, via a renal sympathetic nerve action (16). Renal denervation has been documented to delay the onset and attenuate the severity of some forms of hypertension of different pathogenesis $(13,17)$. The significance of the present results is that they support an important role for renal sympathetic nerve activity in hypertension induced by DOCA and salt overload, as shown previously (18). It appears that DOCA-salt treatment increases plasma sodium content by increasing renal tubular reabsorption of sodium via a renal nerve pathway (19). Sodium retention is facilitated by increases in renal sympathetic nervous activity by actions due to a direct tubular effect (16), and renal vasoconstriction (20). The present results clearly demonstrate that the blunted renal sympathetic activity can interfere with blood pressure only, with no influence on cardiac hypertrophy, corroborating the concept that factors other than pressure overload may influence the development of cardiac mass. In this situation, the DOCA-salt treatment increases the sympathetic activity to the heart, which in turn may elicit cardiac hypertrophy. In this regard, changes in nor-

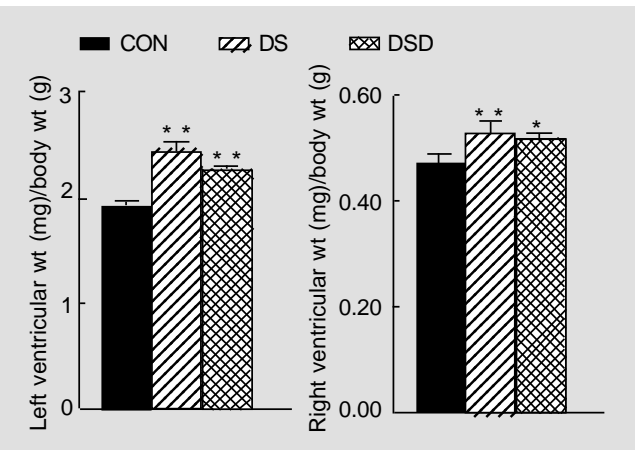

Figure 1 - Effect of renal denervation $(\mathrm{DSD}, \mathrm{N}=9$ ) on ratios of left and right ventricular weight (wt) of deoxycorticosterone-salt (DS, $N=11$ ) hypertensive and time-match control ( $\mathrm{CON}, \mathrm{N}=9$ ) rats. Values are reported as the mean \pm SEM. ${ }^{*} \mathrm{P}<0.05$ and ${ }^{* *} \mathrm{P}<0.01$ compared to control group values.
Table 1 - Influence of renal denervation on cardiovascular parameters of uninephrectomized Wistar rats with or without DOCA-salt treatment.

The measurements were performed after 15 days of DOCA-salt treatment. The groups of rats studied were: sham-denervated with vehicle treatment (control, $N=9$ ), sham-denervated with DOCA-salt treatment (DOCA-salt, $N=11$ ) and denervated with DOCA-salt treatment (DOCA-salt denervation, $\mathrm{N}=9$ ) groups. Values are reported as the mean \pm SEM. ${ }^{*} P<0.05$ and ${ }^{* *} P<0.01$ compared to control group values; ${ }^{+} P<0.05$ and ${ }^{++} P<0.01$ compared to DOCA-salt group values

\begin{tabular}{llll}
\hline Measurements & \multicolumn{3}{c}{ Groups } \\
\cline { 2 - 4 } & Control & DOCA-salt & DOCA-salt denervation \\
\hline MAP (mmHg) & $113 \pm 4.0$ & $157 \pm 5.5^{* *}$ & $122 \pm 4.5^{++}$ \\
HR (beats/min) & $347 \pm 6.0$ & $365 \pm 14.5$ & $359 \pm 13.5$ \\
Body weight $(\mathrm{g})$ & $286 \pm 11$ & $275 \pm 3.0$ & $271 \pm 6.0$ \\
Left ventricular weight $(\mathrm{mg})$ & $551 \pm 13.5$ & $670 \pm 21^{* *}$ & $615 \pm 11^{*+}$ \\
Right ventricular weight $(\mathrm{mg})$ & $137 \pm 3.0$ & $147 \pm 3.0^{*}$ & $142 \pm 4.5$
\end{tabular}

epinephrine content related to blood pressure have been documented in cardiac tissues from DOCA-salt rats as a consequence of augmented norepinephrine turnover induced by a chronic general increase in sympathetic activity (21). In addition, studies performed by Cabral et al. (8) showed a rapid onset cardiac hypertrophy in sinoaortic baroreceptor denervated rats. It is well known that sinoaortic denervation elicits sympathetic hyperactivity (22).

We have shown that an increase in arterial pressure level is not responsible for cardiac hypertrophy, which may be more related to other mechanisms paralleling DOCAsalt hypertension, such as a possible increase in cardiac sympathetic activity. 


\section{References}

1. Seen S \& Tarazi RC (1986). Cardiovascular hypertrophy in spontaneously hypertensive rats. Journal of Hypertension, 4: 123126.

2. Dzau VJ (1988). Cardiac renin-angiotensin system: molecular and functional aspects. American Journal of Medicine, 8 (Suppl $3 A): 22-26$.

3. Bissoli NS, Moyses MR, Vasquez EC \& Cabral AM (1991). Captopril prevents ventricular hypertrophy in sinoaortic denervated rats. Brazilian Journal of Medical and Biological Research, 24: 191-194.

4. Caldarera CM, Giorgi PP \& Casti A (1970). The effect of noradrenaline on polyamine and RNA synthesis in the chick embryo. Journal of Endocrinology, 46: 115-116.

5. Ostman-Smith I (1981). Cardiac sympathetic nerves as the final common pathway in the induction of adaptative cardiac hypertrophy. Clinical Science, 61: 265272.

6. Saavedra JM \& Krieger EM (1987). Early increase in adrenomedullary catecholamine synthesis in sinoaortic denervated rats. Journal of the Autonomic Nervous System, 18: 181-183.

7. Irigoyen MC, Cestari IA, Moreira ED, Oshiro MS \& Krieger EM (1988). Measurements of renal sympathetic nerve activity in conscious sinoaortic denervated rats. Brazilian Journal of Medical and Biological Research, 21: 869-872.

8. Cabral AM, Vasquez EC, Mill JG \& FuturoNeto HA (1983). Ventricular hypertrophy in sinoaortic devervated rats. Brazilian
Journal of Medical and Biological Research, 16: 353-356.

9. Taylor PB \& Tang Q (1984). Development of isoproterenol-induced cardiac hypertrophy. Canadian Journal of Physiology and Pharmacology, 62: 384-389.

10. Yamori Y, Kihara M, Ikeda K, Ooshima A \& Tarazi RC (1980). Cardiac hypertrophy in early hypertension. Japonese Heart Journal, 21: 566-570.

11. Johnson MD, Grignolo A, Kuhn CM \& Schanberg SM (1983). Hypertension and cardiovascular hypertrophy during chronic catecholamine infusion in rats. Life Sciences, 33: 169-180.

12. Newling RP, Fletcher PJ, Contis M \& Shaw J (1989). Noradrenaline and cardiac hypertrophy in the rat: changes in morphology, blood pressure and ventricular performance. Journal of Hypertension, 7: 561-567.

13. Katholi RE, Naftilan AJ \& Oparil S (1980). Importance of renal sympathetic tone in the development of DOCA-salt hypertension in the rat. Hypertension, 2: 266-273.

14. DiBona GF \& Sawin L (1983). Renal nerves in renal adaptation to dietary sodium restriction. American Journal Physiology, 245: F322-F328.

15. Guyton AC (1990). Long-term arterial blood pressure control: an analysis from animal experiments and computer and graphic models. American Journal Physiology, 259: R865-R877.

16. DiBona GF, Zambraski EJ, Aguilera AJ \& Kaloyanides GJ (1977). Neurogenic con- trol of renal tubular sodium reabsorption in the dog. Circulation Research, 40: I127-I-130.

17. Matsuoka $H$, Nishida $H$, Nomura G, Van Vliet BN \& Toshima H (1994). Hypertension induced by nitric oxide synthesis inhibition is renal nerve dependent. Hypertension, 23 (Part 2): 971-975.

18. Musso MN, Vasquez EC, Carvalhinho FB, Bissoli NS \& Cabral AM (1990). Chlorthalidone alters the vascular reactivity of Docsalt hypertensive rats to norepinephrine. Brazilian Journal of Medical and Biological Research, 23: 999-1003.

19. Cabral AM, Musso MN, Bissoli NS, Carvalhinho FB \& Vasquez EC (1992). Chlorthalidone reduces vascular hyperresponsiveness in Doca-salt hypertensive rats. Clinical and Experimental Hypertension. Theory and Practice, A14: 667-683.

20. Schrier RW (1974). Effects of adrenergic nervous system and catecholamines on systemic and renal hemodynamics, sodium and water excretion and renin secretion. Kidney International, 6: 291-306.

21. Doyle AE (1968). Endogenous-catecholamines content of cardiac muscle in sodium-loaded and sodium depleted rats. Lancet, 1: 1399-1400.

22. Vasquez EC \& Krieger EM (1982). Decreased chronotropic responses to adrenergic stimulation following sinoaortic denervation in the rat. Brazilian Journal of Medical and Biological Research, 15: 377 387. 